\title{
Convectively Coupled Kelvin Waves in an Idealized Moist General Circulation Model
}

\author{
DARGAN M. W. FRIERSON \\ University of Chicago, Chicago, Illinois
}

(Manuscript received 26 April 2006, in final form 3 October 2006)

\begin{abstract}
The dynamics of convectively coupled Kelvin waves and their dependence on convection scheme parameters are studied within a simplified moist general circulation model. The model consists of the primitive equations on the sphere over zonally symmetric aquaplanet, slab mixed layer ocean boundary conditions, and idealized physical parameterizations including gray radiative transfer and a simplified Betts-Miller convection scheme. This framework allows the authors to study the dependence of Kelvin waves on quantities such as the gross moist stability in a clean manner.

A control simulation with the model produces convectively coupled Kelvin waves that are remarkably persistent and dominate the variability within the Tropics. These waves propagate with an equivalent depth of $\approx 40 \mathrm{~m}$. Linear regression analysis with respect to a Kelvin-filtered time series shows that the waves are driven by evaporation-wind feedback and have structures broadly consistent with theoretical predictions for Kelvin waves.

Next, the determination of the speed and structure of the Kelvin waves is studied by examining the response of the waves to changes in convection scheme parameters. When the convective relaxation time is lengthened, the waves are damped and eventually are completely eliminated. The propagation speed additionally increases with longer relaxation time. Then changes to a convection scheme parameter that essentially controls the fraction of convective versus large-scale precipitation are examined. When some large-scale precipitation occurs, the waves increase in strength, propagate more slowly, and move to larger scales. However, when mostly large-scale precipitation occurs, the Kelvin wave disappears, and the Tropics are dominated by tropical storm-like variability. The decrease in speed is related here to the gross moist stability of the atmosphere, which is reduced with increased large-scale precipitation.
\end{abstract}

\section{Introduction}

The importance of tropical intraseasonal variability (ISV) for phenomena such as monsoon onset, El Niño/ Southern Oscillation, rainfall patterns in the Tropics as well as the extratropics, and intraseasonal predictability in general has been well-established (see, e.g., Waliser et al. 2003). It is also well known that current general circulation models (GCMs) simulate tropical variability rather poorly (Slingo et al. 1996; Lin et al. 2006). Specifically, most GCMs tend to underestimate the variance present in the Madden-Julian oscillation and the equatorial wave spectrum, including the Kelvin wave that we focus on in this study. Further, the propagation speeds of simulated equatorial waves are commonly found to be too fast when compared with observations.

Corresponding author address: Dargan M. W. Frierson, 5734 S. Ellis Avenue, Chicago, IL 60637.

E-mail: frierson@geosci.uchicago.edu
Unfortunately, because of the complexity of GCMs, the reasons for these deficiencies remain somewhat obscure. Even broad classifications of the differences among model simulations can be difficult. The convection scheme would appear to be the most important ingredient for simulation of equatorial waves, as the coupling of the waves with convective processes is quite intimate. However, even making classifications as broad as closure is not always clear and has changed with time: while Slingo et al. (1996) found that GCMs with moisture convergence closures in their convection schemes performed worse, Lin et al. (2006) found moisture convergence convection schemes produced the best tropical variability.

Many GCM studies have suggested improvements based on specific modifications to a particular convection scheme: for instance, the entrainment-limiting scheme of Tokioka et al. (1988) is often used within mass flux schemes to provide increased tropical variability. Simulations with full GCMs over idealized

DOI: $10.1175 / J A S 3945.1$

(C) 2007 American Meteorological Society 
boundary conditions can be useful in understanding the dynamics of simulated ISV as well. The aquaplanet study of Lee et al. (2001) shows that GCM simulated ISV with cloud-radiative interactions in this geometry can be improved by making alterations to a parameter in the large-scale condensation scheme. The study of Lee et al. (2003) finds that simulated ISV is largely sensitive to convection scheme, and that schemes in which it is more difficult to convect produce stronger variability.

Simple models can additionally provide suggestions for the improvement of GCM simulations of tropical ISV. For instance, the evaporation-wind feedback mechanism for propagation (Neelin et al. 1987; Emanuel 1987) might suggest examination of the surface flux parameterization to ameliorate the simulation of convectively coupled waves; the cloud-radiative feedback mechanism of Raymond (2001) would point to the cloud parameterization for possible improvements.

We argue that an additional important piece of this hierarchy should be idealized GCMs that can bridge the gap between simple models and full GCMs. In this study we use the model introduced in the study of Frierson et al. (2006), which uses the full primitive equations, with aquaplanet boundary conditions, gray radiative transfer, and idealized parameterizations of moisture and other physical processes. There is a strong convectively coupled Kelvin wave in this model and we focus on the dynamics of this wave. Few studies of ISV have been made in models of this sort, partially because there are few such models which have a treatment of moist physics. This model is only a piece of a hierarchy, and the results from this become most useful upon comparison with full GCMs, simple theories, and observations.

\section{a. Observations and simple theories of convectively coupled waves}

Observations of convectively coupled waves and tropical ISV have improved dramatically in recent years. The study of Wheeler and Kiladis (1999) showed that the full equatorial wave spectrum predicted in Matsuno (1966) can be seen in satellite data by filtering away the background spectrum, including Kelvin waves, equatorial Rossby waves, mixed Rossby-gravity waves, and inertia gravity waves. The phase speeds of these waves are significantly reduced with respect to dry predictions however: the interaction with convection creates equivalent depths between 12-50 m for all waves as compared with values around $200 \mathrm{~m}$ for dry waves.

There are two commonly quoted theories for the reduction in wave speeds in convectively coupled waves as compared to dry waves. The first is that moisture effectively reduces the static stability that is felt by waves. In regions of upward motion, latent heat is released as parcels become saturated and moisture is condensed out. This heat causes parcels to become more buoyant, thereby effectively reducing the static stability they feel. That a small, positive value for the moist stability can be a relevant quantity for the Tropics was shown by Neelin and Held (1987), who suggested the gross moist stability as a diagnostic, an integrated measure of the moist stability felt by the flow. Lin et al. (2006) have shown that most GCMs give the same equivalent depth for all their waves, suggesting that they each have a gross moist stability value that is felt by all the waves. An additional theory for the reduction in speed of waves is that of Mapes (2000), who suggests that the higher mode structure in the vertical is responsible for the reduced speeds. The second baroclinic mode dry gravity wave speed is approximately 20 $\mathrm{m} \mathrm{s}^{-1}$, which is similar to the speed of moist Kelvin waves seen in observations. See Wang (2005) for more discussion on these theories, and theories for the energy sources of the waves.

Follow-up observational studies to Wheeler and Kiladis (1999) have examined the structure of equatorial waves in detail. Wheeler et al. (2000) performed regression analysis of reanalysis data with respect to filtered time series to create typical structures of each of the wave types, and studied Kelvin waves over the Indian Ocean. Straub and Kiladis (2002) studied the detailed structure of the dynamical fields associated with a single Kelvin wave event in the eastern Pacific. This study shows that the dynamical fields predicted by shallow water theory (Matsuno 1966; Gill 1980) can be broadly observed within actual equatorial waves. For instance, despite the hemispherically asymmetric nature of the eastern Pacific intertropical convergence zone (ITCZ), dynamical fields such as surface pressure and zonal winds exhibit an anomaly pattern that is symmetric about the equator.

Key differences from various theoretical predictions are highlighted in the study of Straub and Kiladis (2003). This study of regressed reanalysis data indicates that shallow convection leads the deep convective center of Kelvin waves in the central Pacific, and acts to propagate moisture upward. A stratiform cloud deck follows the wave. There is a higher-mode vertical structure implied by the stratiform and shallow components, meaning the wave's temperature and velocity perturbations deviate from those predicted by first baroclinic mode shallow water theory. Aspects of each of the primary theories for propagation of these waves, namely wave-conditional instability of the second kind (CISK; 
Lindzen 1974), evaporation-wind feedback (Neelin et al. 1987; Emanuel 1987), and stratiform instability (Mapes 2000), can be seen in these observations.

\section{b. Outline}

In section 2 of this paper, we give a description of the model used in these simulations. Then in section 3 we provide an analysis of the convectively coupled Kelvin waves in a control simulation with the model. In section 4 we present simulations varying the convective relaxation time in the convection scheme. In section 5 we vary the fraction of large-scale precipitation in the model, and analyze these simulations. We conclude in section 6 .

\section{Model description}

As mentioned in the introduction, due to the extreme complexity of full GCM simulations, we have found it useful to study a GCM of intermediate complexity, with idealized physical parameterizations, to isolate particular physical processes, to improve the ease of interpretation of results, and to help develop and compare with simple models (Frierson et al. 2006, 2007; Garner et al. 2007; Frierson 2007). The primary simplification of this model is gray radiative transfer, which means that radiative fluxes are only a function of temperature. For convectively coupled waves, while radiative feedbacks may be important to some extent, many simple models for these waves use similarly idealized parameterizations of radiative transfer. We additionally use a simplified Betts-Miller convection scheme, which we develop and test in Frierson (2007). We use this scheme because of the simplicity in its formulation, relatively small number of parameters, and reproducibility of results. The recent review by Arakawa (2004) shows that most convection schemes can be interpreted as relaxation schemes similar to the Betts-Miller scheme, and the observations of Bretherton et al. (2004) suggest a Betts-Miller-type scheme may be justified by observations as well. Further, our experiments with full GCM convection schemes suggest a wide range of sensitivities to a multitude of parameters, many of which are often undocumented in studies that use this scheme. We therefore believe the simplified Betts-Miller scheme is useful for intermediate complexity modeling. It is important to note that this GCM can be systematically expanded into a full GCM by progressively adding model physics, and we believe that the results presented here become most fruitful when such comparisons are made.

We give a summary of the model physics here. A full description of the model is given in Frierson et al. (2006), with the exception of the convection scheme which can be found in Frierson (2007). To summarize, the model consists of gray radiative transfer, so water vapor, clouds, and other constituents have no effect on radiative transfer. The solar fluxes are zonally and hemispherically symmetric, and are designed to approximate the annual mean net top of atmosphere flux. There is a specified amount of shortwave absorption within the atmosphere, as in Frierson (2007). Surface fluxes are calculated with a simplified Monin-Obukhov scheme with drag coefficients a function of the height of the lowest level and the surface Richardson number, and equal roughness lengths for momentum, temperature, and humidity. We calculate boundary layer diffusive fluxes with a K-profile scheme up to a calculated boundary layer depth, defined as the lowest height at which a critical bulk Richardson number is exceeded. We use an analytic Clausius-Clapeyron equation to calculate saturation specific humidities.

The simplified Betts-Miller (SBM) convection scheme (Betts 1986; Betts and Miller 1986; Frierson 2007) relaxes temperature and humidity to equilibrium profiles when there is convective available potential energy (CAPE). The form of this relaxation is

$$
\begin{gathered}
\delta T=-\frac{T-T_{\mathrm{ref}}}{\tau_{\mathrm{SBM}}} \\
\delta q=-\frac{q-q_{\mathrm{ref}}}{\tau_{\mathrm{SBM}}},
\end{gathered}
$$

with $T_{\text {ref }}$ a moist adiabat from a surface parcel, that is then corrected to satisfy enthalpy conservation, and $q_{\text {ref }}$ a specified relative humidity with respect to the moist adiabat. The convective relaxation time $\tau_{\mathrm{SBM}}$ and the reference relative humidity $\mathrm{RH}_{\mathrm{SBM}}$ are the two parameters of the convection scheme. Shallow (nonprecipitating) convection is performed in cases where there is instability but not enough moisture to convect. In the simulations presented here, we utilize a scheme that lowers the depth of shallow convection from the level of zero buoyancy to ensure that the net precipitation is zero; this is known as the shallower scheme in Frierson (2007).

In Frierson (2007), we show that the primary sensitivity of the zonally averaged circulation is to the fraction of large-scale versus convective precipitation. As compared to simulations with primarily convective precipitation, simulations with mostly large-scale precipitation exhibit a stronger Hadley circulation mass transport, weaker Hadley circulation energy transports, a smaller gross moist stability, and more tropical storm- 


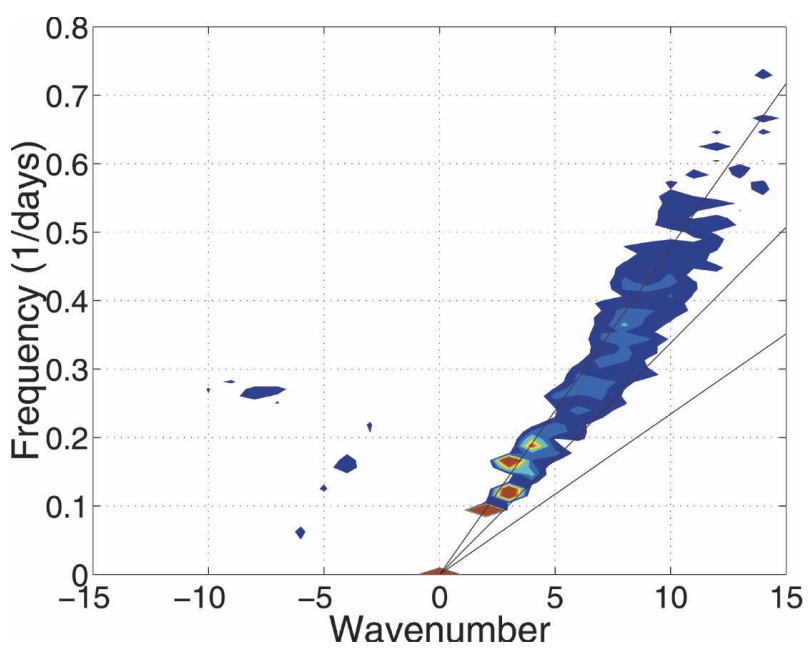

FIG. 1. Filtered wavenumber-frequency spectrum for precipitation in the control case, calculated following Wheeler and Kiladis (1999). Positive wavenumbers correspond to eastward propagation in this plot.

like activity. This transition between convective- and large-scale-dominated regimes typically can occur abruptly in parameter space. More large-scale precipitation can be obtained by varying either of the convection scheme parameters: increasing the relative humidity parameter $\mathrm{RH}_{\mathrm{SBM}}$, or increasing the relaxation time parameter $\tau_{\mathrm{SBM}}$. The sensitivity of the zonally averaged circulation to convection scheme parameters in general however is small, provided large-scale condensation is not allowed to occur.

The simulations here use all of the control simulation values in Frierson et al. (2006), except for the shortwave radiation alteration in Frierson (2007). The control values of the convection scheme parameters are $\tau_{\mathrm{SBM}}=2 \mathrm{~h}$ and $\mathrm{RH}_{\mathrm{SBM}}=0.6$; the latter is taken to be smaller than that used in Frierson (2007) to allow more leeway in changing the convective relaxation time $\tau_{\mathrm{SBM}}$ before large-scale precipitation occurs.

To provide better statistics for the spectral and regression diagnostics, the simulations are run for longer than in Frierson et al. (2006) and Frierson (2007): the climatologies obtained below are averaged over a 4320 day period following a 360-day spinup period. The model resolution is T42 with 25 vertical levels, following that of Frierson (2007).

\section{Control simulation Kelvin waves}

A filtered wavenumber-frequency spectrum plot for precipitation in the control simulation of the model, obtained by the method of Wheeler and Kiladis (1999), is given in Fig. 1. To construct this plot, we first calcu- late a wavenumber-frequency spectrum [see Hayashi (1982) for details on this] for the precipitation at all latitudes between $15^{\circ} \mathrm{N}$ and $15^{\circ} \mathrm{S}$ using 96-day windows, which overlap by 60 days. Wheeler and Kiladis (1999) use outgoing longwave radiation in their study; however precipitation is the diagnostic most analogous with outgoing longwave radiation in a model without clouds. The spectra are then averaged in latitude between $15^{\circ} \mathrm{N}$ and $15^{\circ} \mathrm{S}$ to create the base spectrum. Since we average in latitude, this corresponds to the symmetric part of the spectrum in Wheeler and Kiladis (1999); since our model is forced purely symmetrically, all of the substantial variance is in the symmetric part. The base spectrum is then smoothed repeatedly to create a background spectrum. Finally, the base spectrum is divided by the background spectrum. The contouring begins at 1.2 in this plot.

An eastward propagating, nondispersive wave is clearly the predominant variability within Fig. 1. This corresponds to the convectively coupled equatorial Kelvin wave seen in Wheeler and Kiladis (1999). Other waves which are seen in observations (e.g., equatorial Rossby, inertia-gravity waves) are mostly absent from this plot. The dispersion curves for Kelvin waves with equivalent depths of 12,25 , and $50 \mathrm{~m}$ are plotted. The control simulation has most of its variance centered around an equivalent depth of approximately $40 \mathrm{~m}$, corresponding to a speed of $19.8 \mathrm{~m} \mathrm{~s}^{-1}$, only slightly faster than observed speeds. There is some indication of the wave propagating more slowly at larger scales.

This Kelvin wave dominates the variability of most fields in the Tropics, and can be seen clearly in surface pressure, zonal winds, temperature, and humidity, among other fields. As an example of this, we plot a Hovmöller (longitude-time) diagram of precipitation at the equator for the control case in Fig. 2. This plot displays unfiltered daily precipitation data for 100 days of simulation. Crests and peaks of Kelvin waves can be picked out at nearly every instant in time of the simulations. The waves are also remarkably persistent, with single waves often trackable for several complete transits around the equator.

We next examine the typical structure of the Kelvin waves by constructing a composite of the waves. We calculate this by the method of Wheeler et al. (2000), which consists of first constructing a Kelvin-filtered time series, and then correlating all other variables against this. The time series is chosen to be the pressure velocity at $500 \mathrm{hPa}$, again chosen for similarity with OLR in a model but without the positive semidefiniteness of the precipitation. The filtering is accomplished by constructing a wavenumber-frequency spectrum us- 


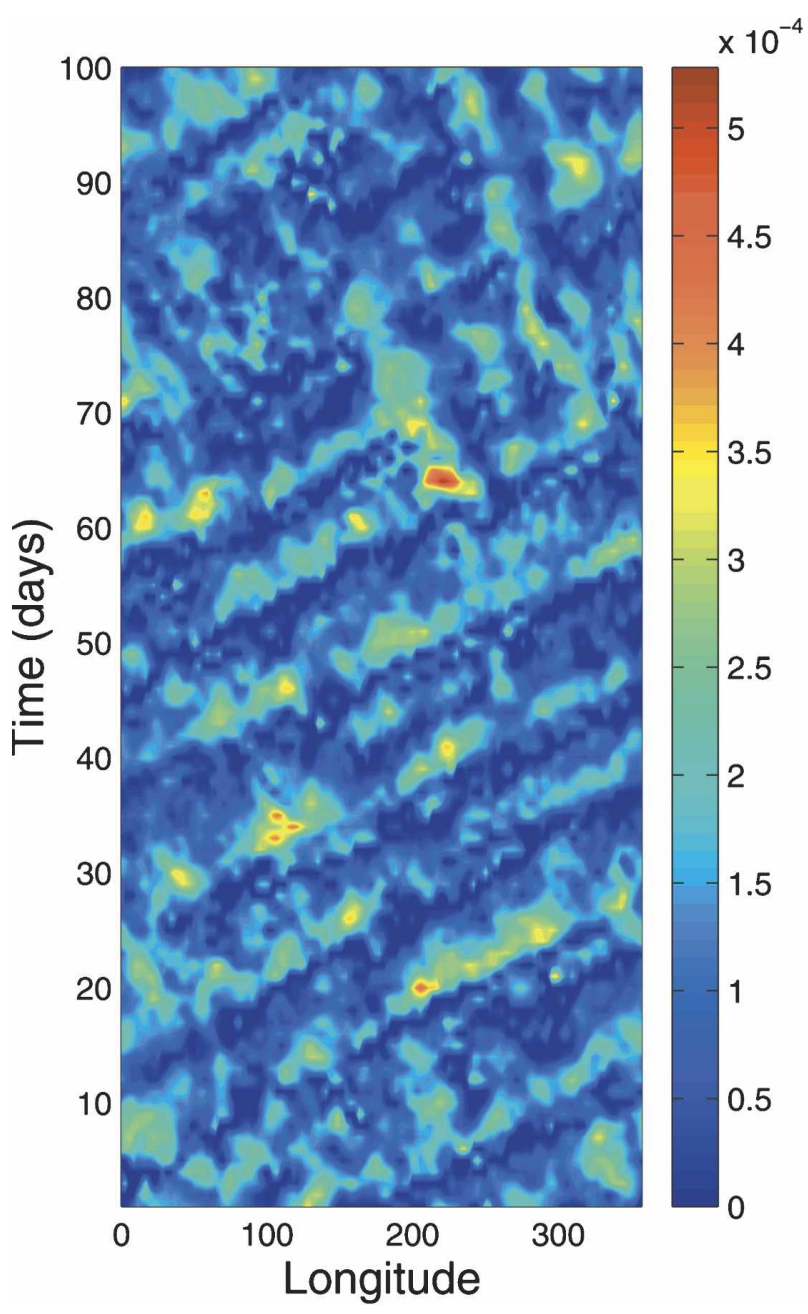

FIG. 2. Hovmöller (longitude-time) diagram of precipitation $\left(\mathrm{kg} \mathrm{m}^{-2} \mathrm{~s}^{-1}\right)$ at the equator in the control case for 100 days of simulation.

ing the entire time series, then zeroing out the westward propagating signal and eastward propagating signals with any of the following properties: frequency below $1 / 30$ day $^{-1}$ or above $1 / 2.5$ day $^{-1}$, wavenumber below 1 or above 14, and Kelvin wave equivalent depth above $90 \mathrm{~m}$ or below $8 \mathrm{~m}$. An inverse transform is then used to reconstruct the filtered time series. All fields are regressed against the filtered time series at a base point on the equator (where the Kelvin wave variance is maximum). The plots are centered about the base point, and scaled to twice the standard deviation at the base point.

Figure 3 shows composited fields in latitude and longitude. The precipitation and surface winds are plotted in Fig. 3a. The precipitation is maximum at the base point, where there is additionally strong convergence of the surface winds. The precipitation anomaly is closely confined to within $10^{\circ} \mathrm{N} / \mathrm{S}$ of the equator. Zonally, the positive phase extends to approximately $20^{\circ}$ to the west, and slightly farther to the east, to approximately $30^{\circ}$ at the equator. The positive precipitation anomalies take on somewhat of a V shape on the western end. Negative precipitation anomalies are especially intense on the western (trailing) side of the maximum. The surface wind anomalies are primarily zonal, with a particularly strong signal on the equator. There is a meridional component of the surface winds however: the convergence of the meridional surface winds ahead of the wave, with divergence trailing indicates that the frictional convergence mechanism (Wang 1988) is active to some extent in powering the waves (although this is not the primary driver, as we show later).

The composited midtropospheric pressure velocity anomaly is given in Fig. 3b. This essentially follows the precipitation anomalies, with strong upward motion (negative pressure velocity) around the base point, and broader anticorrelated regions surrounding. The Vshape also seen in precipitation is more prominent on the western side, and can additionally be seen in downward motion on the eastern side. This shape is likely due to frictional convergence as well (see, e.g., Wang and Rui 1990). The surface pressure is given in Fig. 3c. These anomalies are largely in quadrature with the precipitation, with low pressure anomalies leading and high pressure trailing. All of these properties are broadly consistent with theoretical predictions of first baroclinic mode Kelvin waves: vertical motion in quadrature with surface pressure, and surface convergence of the zonal winds at the same location as midtropospheric vertical motion and precipitation.

We focus on the method of propagation of the waves in Fig. 4. The composited precipitation and evaporation along the equator are given in Figs. 4a,b; these plots now include the mean value of the quantity being composited. The evaporation leads the precipitation by just over $20^{\circ}$, which corresponds to approximately 1.5 days at the typical propagation speed of the wave. The amplitude of the evaporation anomaly is significantly smaller than the precipitation anomaly $\left(50 \mathrm{~W} \mathrm{~m}^{-2}\right.$ evaporation anomaly versus $200 \mathrm{~W} \mathrm{~m}^{-2}$ precipitation anomaly), but it is well known that small changes in the distribution of evaporation can lead to large changes in precipitation in GCM simulations of the Tropics (e.g., Numaguti 1993). This is true as well for simple models based on the moist static energy budget that utilize a small gross moist stability (e.g., Neelin and Held 1987). We discuss the gross moist stability in more detail in section 5a. The corresponding change in the tropospheric radiative cooling rate over the period of the wave is significantly smaller than the evaporation (not 

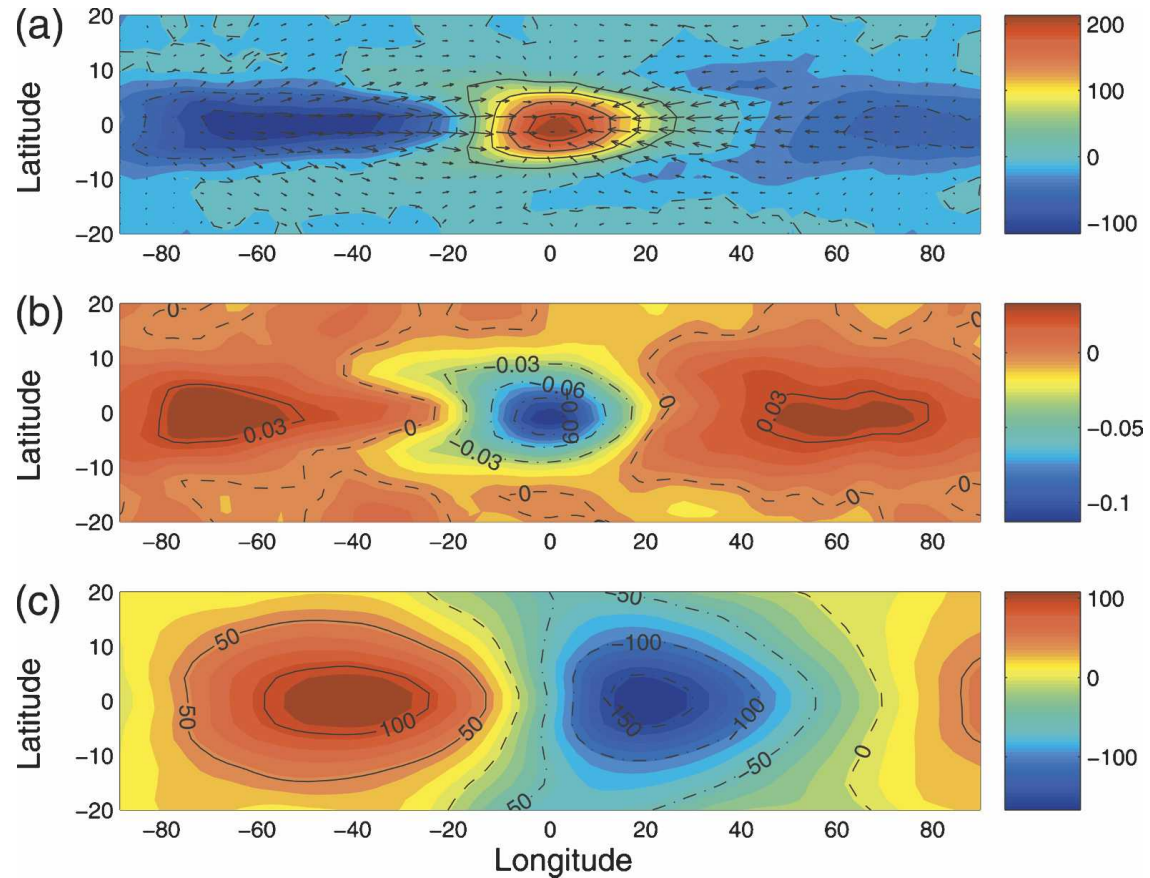

FIG. 3. Control case Kelvin wave composite anomalies for (a) surface wind $\left(\mathrm{m} \mathrm{s}^{-1}\right)$ and precipitation $\left(\mathrm{W} \mathrm{m}^{-2}\right),(\mathrm{b})$ midtropospheric pressure velocity $\left(\mathrm{Pa} \mathrm{s}^{-1}\right)$, and (c) surface pressure $(\mathrm{Pa})$.

shown), which is not surprising with a radiation scheme that does not contain cloud- or water vapor-radiative feedbacks. The other forcing in the moist static energy equation, the sensible heat flux, is relatively small and correlated with the evaporation. Frictional convergence acts to power the waves as well, but the moisture converged in the boundary layer by this feedback is approximately 4 times smaller than the evaporation differences (not shown).

The evaporation maximum leading the precipitation is caused by larger wind speeds near the surface on the eastern side of the wave, in accordance with the evaporation-wind feedback theory (Neelin et al. 1987; Emanuel 1987). The mean surface easterlies at the equator for this simulation are approximately $2.7 \mathrm{~m} \mathrm{~s}^{-1}$, and when surface convergence is superimposed upon this mean wind, the zonal winds vary significantly across the wave (between 0 and $6 \mathrm{~m} \mathrm{~s}^{-1}$; Fig. 4c). Since the winds are primarily zonal in this region, and since evaporation is proportional to the surface wind, this leads to the variation of evaporation following the structure of the surface zonal wind in Fig. 4.

To confirm the evaporation-wind feedback mechanism as the driver of these waves, we have altered the evaporation formulation to suppress the dependence on wind speed by replacing this by a globally averaged value. In this simulation, the Kelvin wave was com- pletely eliminated (not shown). Additional methods to reduce the effectiveness of the evaporation-wind feedback mechanisms include introducing a large gustiness velocity in the evaporation formulation, and reducing the oceanic mixed layer depth to zero. Since evaporation-wind feedback strengthens eastward-propagating waves and weakens westward propagating waves, this feedback is a likely reason why there are no Rossby waves or other westward-propagating waves in Fig. 1. While evaporation-wind feedback may contribute to the growth of Kelvin waves in nature, this theory does not fully explain observed Kelvin waves such as those in Wheeler et al. (2000).

We next focus on the vertical structure of the waves along the equator, starting with the pressure velocity and the specific humidity, shown in Fig. 5. The maximum vertical velocity is in the midtroposphere; however, some higher-mode vertical structure can be seen here as well. Shallow convection leads the maximum precipitation, as seen in observations. Lower tropospheric moisture leads the convection, and is gradually propagated upward by the shallow convection; this preconditions the troposphere for deep convection. Differing from observations here is the lack of a stratiform cloud deck trailing the area of deep convection. It is not surprising that this aspect of observations cannot be captured in our model, which has no condensate. It is 

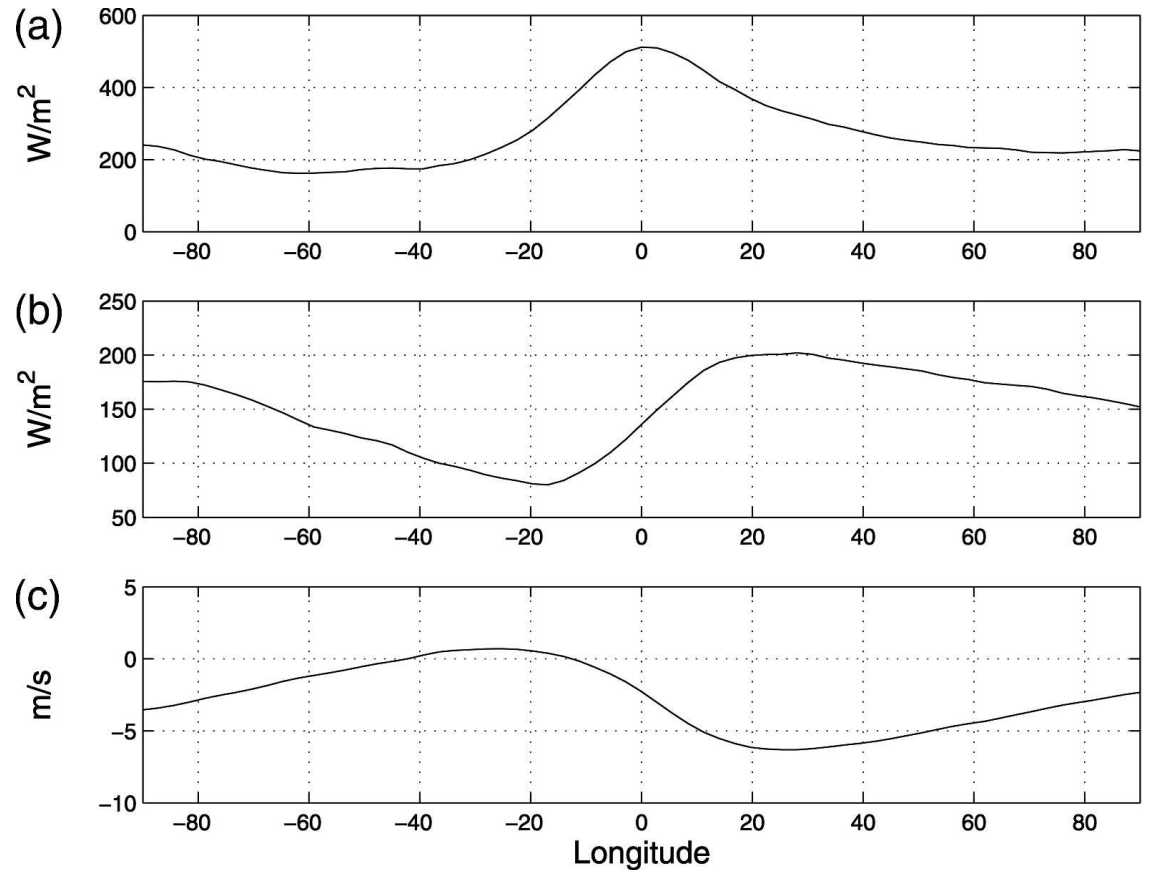

FIG. 4. Control case Kelvin wave composites along the equator for (a) precipitation $\left(\mathrm{W} \mathrm{m}^{-2}\right)$, (b) evaporation $\left(\mathrm{W} \mathrm{m}^{-2}\right)$, and (c) surface wind $\left(\mathrm{m} \mathrm{s}^{-1}\right)$. These composites include the mean value of the field.

however notable that without a sophisticated shallow convection parameterization and with only a simplified Betts-Miller convection scheme, there is some shallow convection seen leading the wave.
We examine the vertical structure of temperature and zonal wind in Fig. 6. In the temperature anomaly, a largely one-signed in the vertical warm anomaly precedes the wave, followed by a cold anomaly. For the

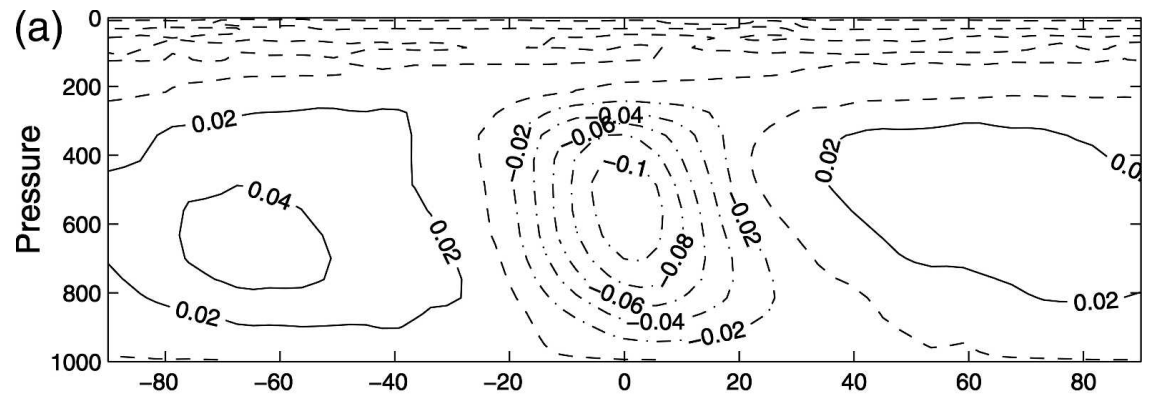

(b) 0

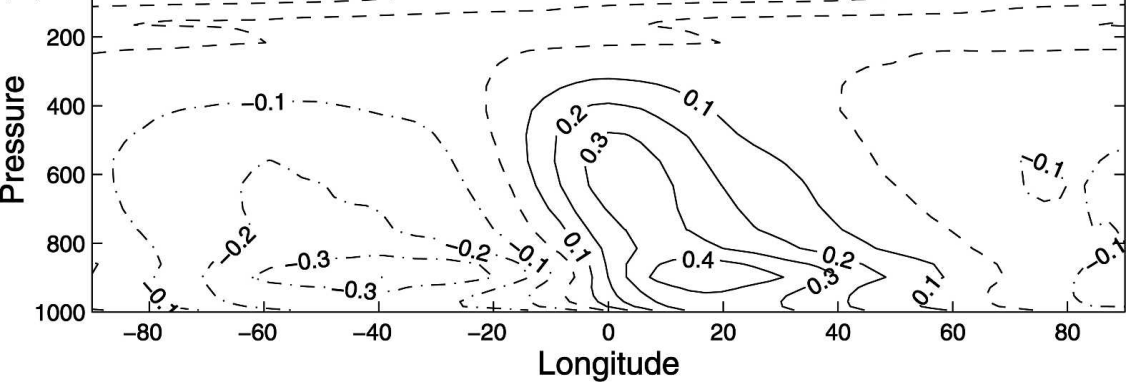

FIG. 5. Control case Kelvin wave composites for (a) pressure velocity anomaly $\left(\mathrm{Pa} \mathrm{s}^{-1}\right.$ ), and (b) specific humidity anomaly $\left(\mathrm{g} \mathrm{kg}^{-1}\right)$. 

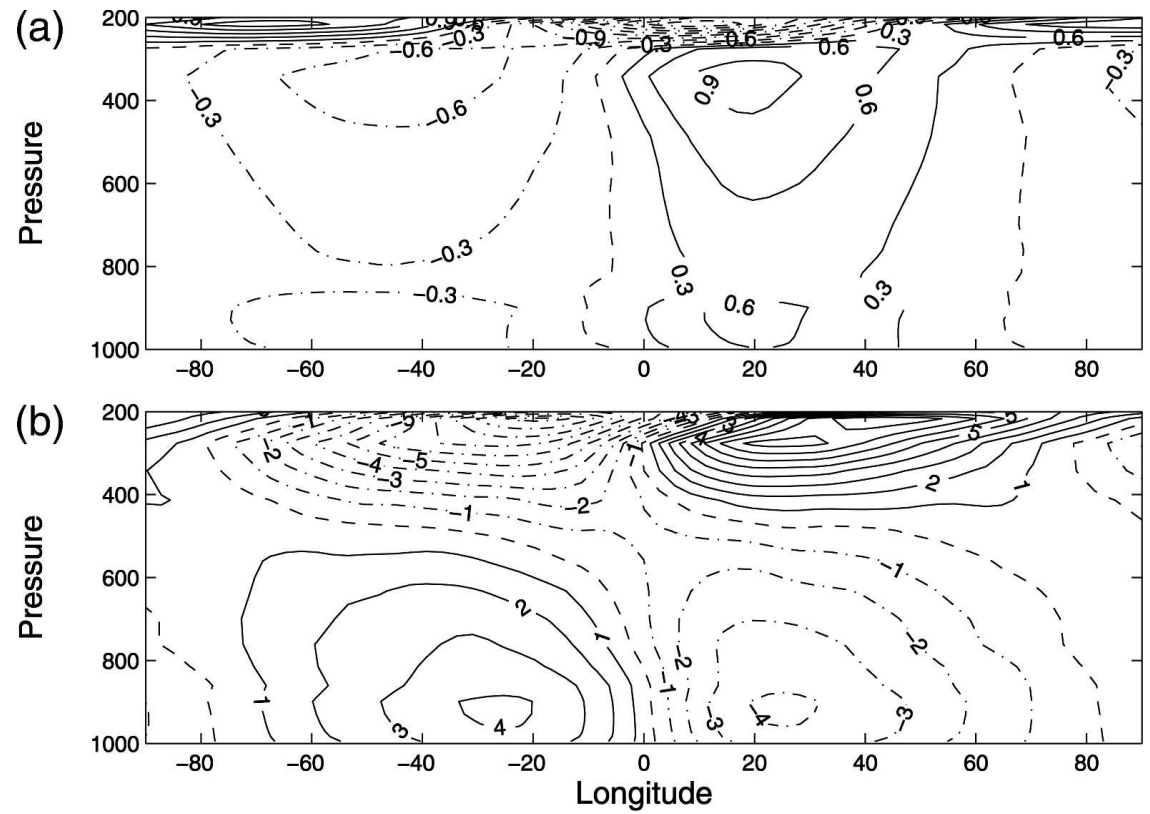

FIG. 6. Control case Kelvin wave composite for (a) temperature anomaly (K) and (b) zonal wind anomaly $\left(\mathrm{m} \mathrm{s}^{-1}\right)$.

zonal wind, the velocities are largely of opposite signs in the upper and lower troposphere. These aspects are consistent with the first-baroclinic mode theoretical predictions for Kelvin waves. This is not, however, consistent with observations, which have much more of a second-baroclinic structure (Wheeler et al. 2000; Straub and Kiladis 2003). The lack of second baroclinic mode structure is the primary deviation of the simulated waves from observations. There is a hint of some higher mode vertical structure with significantly reduced amplitude in our model: for instance, at the base point the temperature perturbations are warmer near the surface, cooler around $800 \mathrm{hPa}$, and warmer in the upper troposphere. The reduced amplitude of the vertical structure indicates that this model has lessened importance of the heating terms that force the second baroclinic mode: shallow convection and stratiform precipitation. Figures $6 a, b$ are truncated near the tropopause due to the strength of the stratospheric anomalies. As in observations, the temperature and wind perturbations become significantly larger as the waves propagate vertically.

\section{Varying convective relaxation time}

We next present simulations varying the convective relaxation time of the simplified Betts-Miller convection scheme, $\tau_{\mathrm{SBM}}$. We increase this from the control value of $\tau_{\mathrm{SBM}}=2 \mathrm{~h}$ to 4 and $8 \mathrm{~h}$ in this set of simula- tions. The wavenumber-frequency spectra for these three simulations are plotted in Fig. 7. There is a significant reduction in amplitude of the variability as the relaxation time is increased. With 4-h relaxation time, the variability is significantly decreased, while at $8 \mathrm{~h}$ the Kelvin wave is nearly eliminated. It is notable that recent studies have suggested that observationally appropriate values of the relaxation time are larger than this, $12-16 \mathrm{~h}$ in the study of Bretherton et al. (2004). We additionally point out the slight increase in speed as the relaxation time is increased: an equivalent depth of $\approx 55$ $\mathrm{m}$ is appropriate for the 4-h relaxation time simulation, and there is a slight indication in this diagram that the speed would be faster than this at $8 \mathrm{~h}$ if the wave were more prominent.

To investigate the dramatic decrease in amplitude of the Kelvin waves with increasing relaxation time, we plot the pressure velocity and temperature composite anomalies at $490 \mathrm{hPa}$ for these simulations in Fig. 8. While the pressure velocity is centered around the base point in each case (where the precipitation is maximum), the temperature anomaly is shifted eastward with longer relaxation time. This phase shift of the temperature anomalies is in accordance with the prediction of Emanuel (1993) (see also Emanuel et al. 1994; Neelin and Yu 1994; Yu and Neelin 1994), which shows that an increased convective relaxation time acts as a damping for evaporation-wind feedback modes. At small convective relaxation time, the temperature is nearly in 
(a)

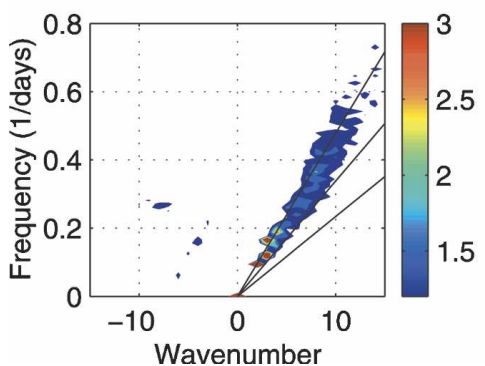

(b)

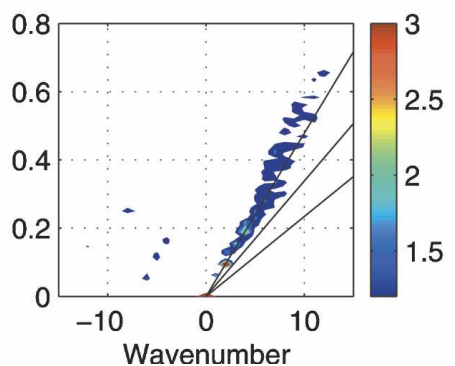

(c)

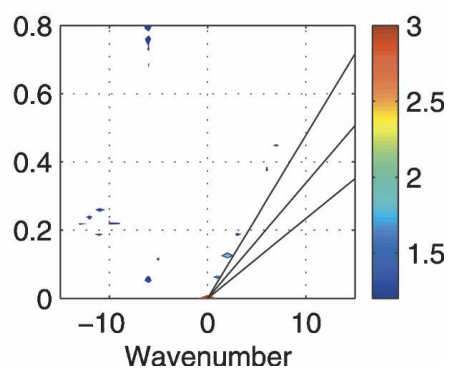

FIG. 7. Space-time spectrum for the simulations varying convective relaxation time $\tau_{\mathrm{SBM}}$ : (a) $\tau_{\mathrm{SBM}}=2 \mathrm{~h}$,

(b) $\tau_{\mathrm{SBM}}=4 \mathrm{~h}$, and (c) $\tau_{\mathrm{SBM}}=8 \mathrm{~h}$.

quadrature with the pressure velocity (and is actually slightly positively correlated with the upward motion); however at higher relaxation time this phase relationship is disrupted in such a way that the temperature is more anticorrelated with the upward motion. This provides an energy sink for the wave, which eventually is sufficient to eliminate the wave completely.

In Fig. 9, we plot the precipitation, evaporation, and surface wind speed for these simulations. While the amplitude of each of these fields is severely reduced with increased convective relaxation time, we focus on the relative shifts in phasing between the fields. As the relaxation time increases, the evaporation moves eastward relative to the precipitation maximum. This is true both for the absolute maximum of evaporation as well as the slope of the evaporation curve at the precipitation maximum. We argue that this increase in eastward offset of the evaporation maximum could explain the increased speed of propagation as $\tau_{\mathrm{SBM}}$ is lengthened. When the evaporation forcing is farther from the core of the wave, the precipitating core of the wave is dragged along more quickly by this forcing. The reason for the increase in evaporation offset can again be traced to the surface wind. With a broader updraft, the surface wind achieves its maximum farther away from the precipitation maximum, causing the evaporation maximum to move similarly. Further, the weaker convergence causes the surface wind to change more gradually about the center of the updraft, causing the smaller slope in evaporation about that location.

That the wave speed depends on the precise phasing of the forcing suggests that to some extent the propagation may be sensitive to details of the parameterizations and boundary conditions. Further a feedback loop for the amplitude is suggested by this behavior that would additionally increase sensitivities: as the wave weakens, the evaporation leads by more, further disrupting the phase relationships. These possible sensitivities to other factors have been confirmed in our tests of other parameters such as mixed layer depth, to which the wave speed and amplitudes are sensitive in complex ways, along the same lines of that described here. However instead of providing a more in-depth investigation into details of the evaporation-wind feedback, to which the relevance to observations remains questionable, we instead next study the influence of the gross moist stability on the Kelvin wave amplitude and speed. We perform these tests by varying the fraction of largescale precipitation with the $\mathrm{RH}_{\mathrm{SBM}}$ parameter, which produces a clear effect on the propagation of Kelvin waves, which we have found to be robust over many additional parameter studies.

\section{Varying fraction of large-scale precipitation}

In this section we show simulations varying the relative humidity of the convective reference profile, the

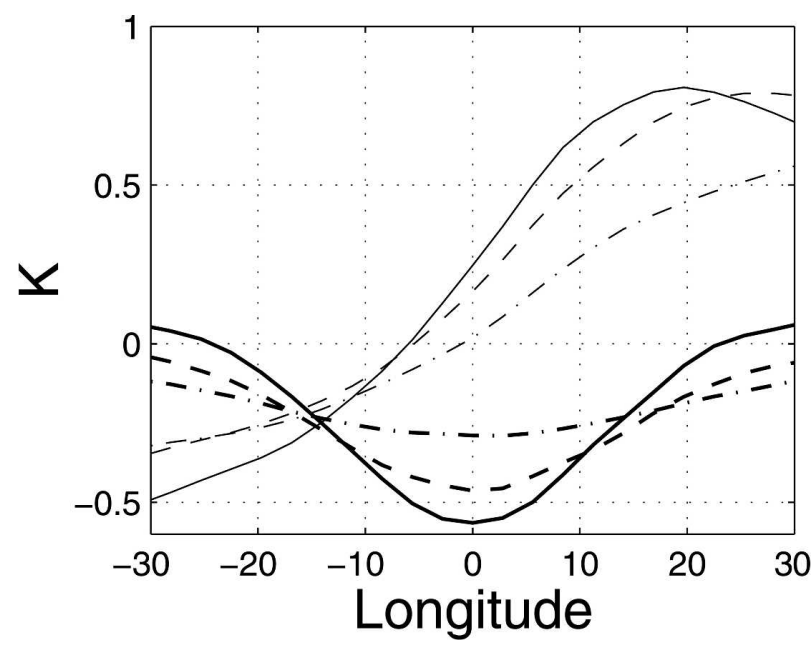

FIG. 8. Composites of temperature (thinner lines, K) and pressure velocity (thicker lines, multiplied by 5 to fit on the axes and in units of $\mathrm{Pa} \mathrm{s}^{-1}$ ) anomalies at $490 \mathrm{hPa}$ for the simulations varying convective relaxation time $\tau_{\mathrm{SBM}}$. Solid: $\tau_{\mathrm{SBM}}=2 \mathrm{~h}$, dashed: $\tau_{\mathrm{SBM}}=4 \mathrm{~h}$, and dashed-dotted: $\tau_{\mathrm{SBM}}=8 \mathrm{~h}$. 

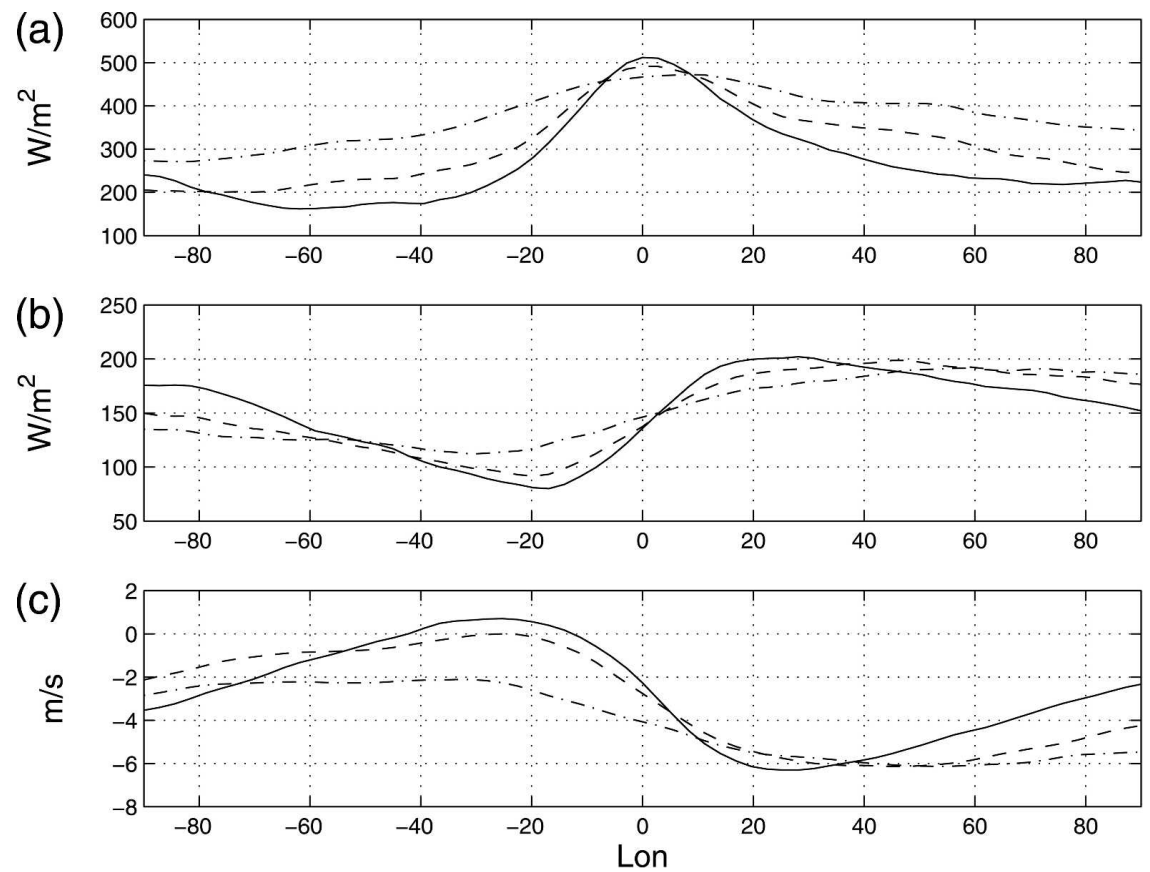

FIG. 9. Composites of precipitation $\left(\mathrm{W} \mathrm{m}^{-2}\right)$, evaporation $\left(\mathrm{W} \mathrm{m}^{-2}\right)$, and surface wind $\left(\mathrm{m} \mathrm{s}^{-1}\right)$ for the simulations varying convective relaxation time $\tau_{\mathrm{SBM}}$. Solid: $\tau_{\mathrm{SBM}}=2 \mathrm{~h}$, dashed: $\tau_{\mathrm{SBM}}=4 \mathrm{~h}$, and dashed-dotted: $\tau=8 \mathrm{~h}$.

$\mathrm{RH}_{\mathrm{SBM}}$ parameter. As mentioned above, we use this parameter to vary the fraction of large-scale precipitation, and analogous results can be derived with other parameter variations that change the proportion of large-scale versus convective precipitation. Unfortunately, transitions from the convective regime to the large-scale regime can happen quickly in parameter space, so tuning to a particular fraction can be difficult. Here we compare the control simulation, $\mathrm{RH}_{\mathrm{SBM}}=0.6$, which has no large-scale precipitation in the Tropics, to simulations with $\mathrm{RH}_{\mathrm{SBM}}=0.8, \mathrm{RH}_{\mathrm{SBM}}=0.85$, and $\mathrm{RH}_{\mathrm{SBM}}=0.95$. The simulation with $\mathrm{RH}_{\mathrm{SBM}}=0.8$ has approximately $0.3 \%$ large-scale precipitation at the equator, while the simulation with $\mathrm{RH}_{\mathrm{SBM}}=0.85$ has $12 \%$, and the simulation with $\mathrm{RH}_{\mathrm{SBM}}=0.95$ has over $99 \%$. All simulations utilize the control value of convective relaxation time, $\tau_{\mathrm{SBM}}=2 \mathrm{~h}$.

In Fig. 10, we show the wavenumber-frequency spectra for the three new simulations. The simulation with $\mathrm{RH}_{\mathrm{SBM}}=0.8$ (Fig. 10a) has several notable differences from the control simulation: first, there is a clear reduction of phase speed of the Kelvin waves, with an equivalent depth of $\approx 30 \mathrm{~m}$ appropriate for this simulation. The Kelvin wave is additionally concentrated at larger scales than in the control simulation, with little to no variance above wavenumber 8 . However, at the wavelengths where the wave is significant, the variability is strengthened greatly. The $\mathrm{RH}_{\mathrm{SBM}}=0.85$ simulation
(Fig. 10b) has many of these same characteristics, but enhanced. Here the Kelvin wave is additionally slowed, with an equivalent depths of $\approx 25 \mathrm{~m}$ giving a good approximation to wave speeds. Further, the variability is again increased significantly in strength at the lower wavenumbers. Additionally in this case there is increased variance in the tropical depression band (westwardpropagating disturbances with periods $\approx 2-5$ days).

Examination of the $\mathrm{RH}_{\mathrm{SBM}}=0.95$ simulation (Fig. 10c) shows that many of these changes to the Kelvin wave are eliminated when solely large-scale precipitation occurs: the Kelvin wave is now essentially nonexistent in this simulation. There remains however enhanced variability within the tropical depression band. The predominance of the small-scale tropical depression-like storms was noted in the large-scale condensation-only simulations of Frierson et al. (2006). Since there is no significant Kelvin wave propagation in this case, we do not include this case in the composite analysis that follows.

To understand the reasons for the enhanced, slower propagating Kelvin waves in the cases with some largescale precipitation, we examine composites of the $\mathrm{RH}_{\mathrm{SBM}}=0.8$ and $\mathrm{RH}_{\mathrm{SBM}}=0.85$ simulations and compare with the control. In Fig. 11 we plot the precipitation, evaporation, and surface wind for these three simulations. The increased amplitude of the wave can be seen in the precipitation distribution (Fig. 11a), 
(a)

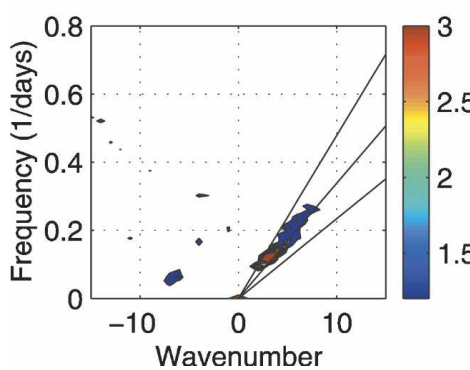

(b)

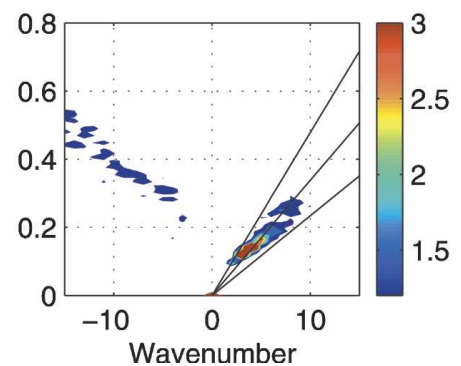

(c)

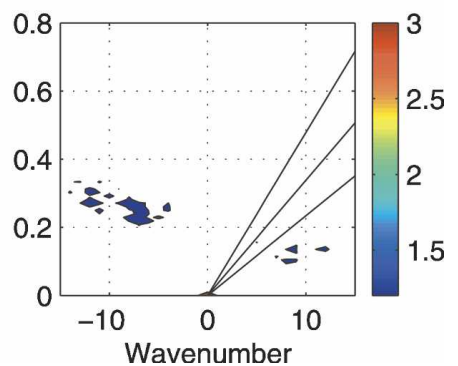

FIG. 10. Space-time spectrum for the simulations varying the relative humidity of the reference profile, $\mathrm{RH}_{\mathrm{SBM}}$ : (a) $\mathrm{RH}_{\mathrm{SBM}}=0.8$, (b) $\mathrm{RH}_{\mathrm{SBM}}=0.85$, and (c) $\mathrm{RH}_{\mathrm{SBM}}=0.95$.

which attains a significantly larger maximum in the $\mathrm{RH}_{\mathrm{SBM}}=0.85$ case $\left(750 \mathrm{~W} \mathrm{~m}^{-2}\right.$ as compared with 500 $\mathrm{W} \mathrm{m}{ }^{-2}$ for the control and $600 \mathrm{~W} \mathrm{~m}^{-2}$ for the $\mathrm{RH}_{\mathrm{SBM}}=$ 0.8 case). Examination of the evaporation fields in Fig. $11 \mathrm{~b}$ shows that this is responsible for neither the increased amplitude, nor the decreased phase speed. The evaporation actually exhibits a decrease in amplitude for the two cases with large-scale precipitation. Further, both the slope of the evaporation curve at zero and the phase lead of the maximum (centered around $20^{\circ}$ ) are similar in all cases, indicating that the method of increase in speed suggested in section 4 is not operating. There is slightly increased surface convergence (Fig. $11 \mathrm{c})$ in the cases with some large-scale precipitation, but the surface wind profiles are also all remarkably similar.

\section{Gross moist stability}

We next introduce the gross moist stability in order to explain the Kelvin wave characteristics. We define the gross moist stability $\Delta m$ following Neelin and Held (1987):

$$
\begin{aligned}
\boldsymbol{\nabla} \cdot \mathbf{V}_{\mathbf{2}} & =\int_{p_{m}}^{p_{s}} \boldsymbol{\nabla} \cdot \overline{\mathbf{v}} \frac{d p}{g} \\
\Delta m & =\int_{0}^{p_{s}} \bar{m} \boldsymbol{\nabla} \cdot \overline{\mathbf{v}} \frac{d p}{g}\left(\boldsymbol{\nabla} \cdot \mathbf{V}_{\mathbf{2}}\right)^{-1},
\end{aligned}
$$
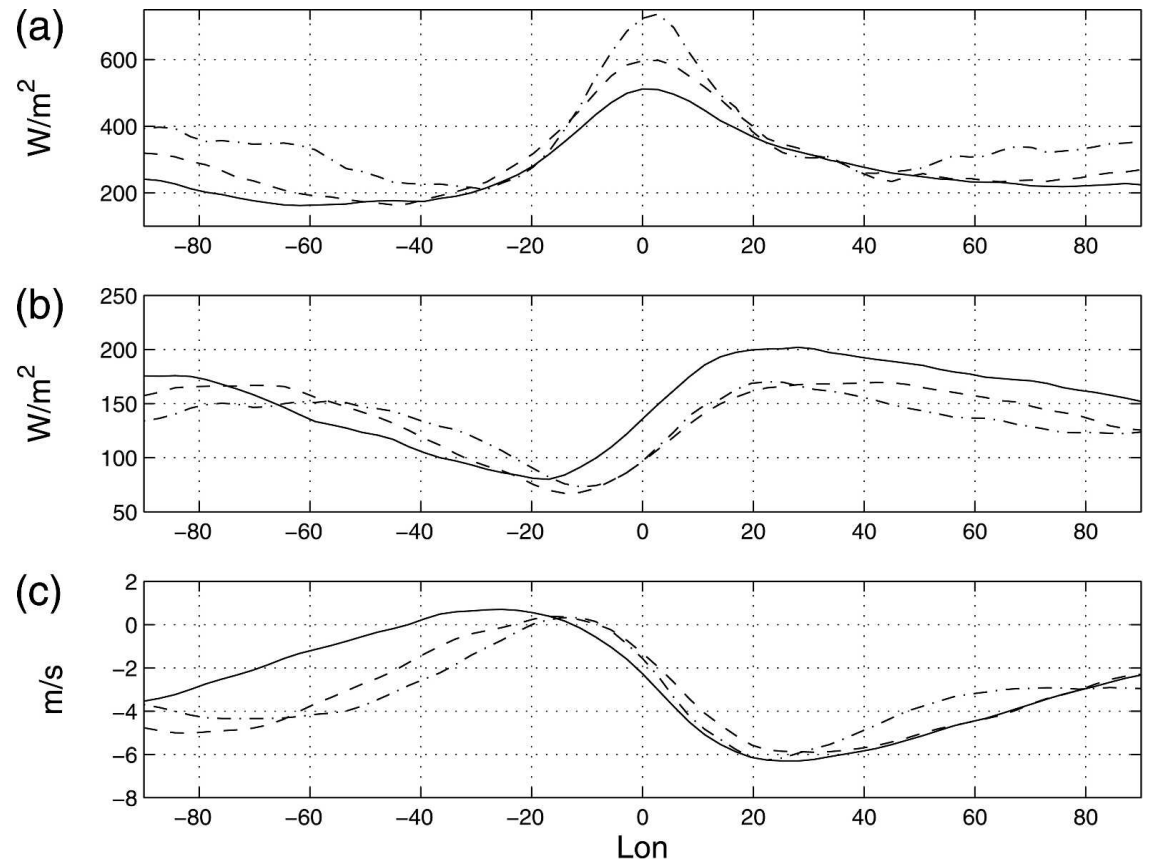

FIG. 11. Composites of (a) precipitation $\left(\mathrm{W} \mathrm{m}^{-2}\right)$, (b) evaporation $\left(\mathrm{W} \mathrm{m}^{-2}\right)$, and (c) surface wind $\left(\mathrm{m} \mathrm{s}^{-1}\right)$ for the $\mathrm{RH}_{\mathrm{SBM}}=0.6$ simulation (solid), the $\mathrm{RH}_{\mathrm{SBM}}=0.8$ simulation (dashed), and the $\mathrm{RH}_{\mathrm{SBM}}=0.85$ simulation (dashed-dotted). 
where overbars denote time means, $p_{s}$ is the surface pressure, $m=c_{p} T+g z+L q$ is the moist static energy, and $p_{m}$ is a midtropospheric level. The midtropospheric level $p_{m}$ is chosen so that the quantity $\boldsymbol{\nabla} \cdot \mathbf{V}_{2}$ is maximized for each column. In first baroclinic mode models of the tropical atmosphere with moisture (Neelin and Zeng 2000; Frierson et al. 2004), the gross moist stability or some analogous quantity determines the speed of convectively coupled equatorial waves by setting the effective static stability in moist regions. Here we compare with the simple theory of Tian and Ramanathan (2003), which gives the following formula for moist Kelvin wave speed:

$$
c=\left[R_{d} \Delta m \Delta p /\left(c_{p} p_{m}\right)\right]^{1 / 2},
$$

where $\Delta m$ is the gross moist stability, $\Delta p$ is the tropospheric depth, and $p_{m}$ is the midtropospheric pressure. The wave speed scales with the square root of the gross moist stability; that is, the equivalent depth $\left(h=c^{2} / g\right)$ scales with the gross moist stability. The dry Kelvin wave in this model follows the same formula with the gross moist stability replaced with the gross dry stability. Using parameter values of $\Delta p=750 \mathrm{hPa}$ and $p_{m}=$ $600 \mathrm{hPa}$ gives a dry wave speed of $49 \mathrm{~m} \mathrm{~s}^{-1}$ when the control case gross dry stability of $27 \mathrm{~K}$ is used. The relevance of the gross moist stability to equatorial waves in the real atmosphere or within GCMs is of yet unproven.

The work of Frierson (2007) studied the dependence of the gross moist stability of the tropical atmosphere on convection scheme parameters. A slightly different definition of the zonal mean gross moist stability (using the meridional velocity instead of the divergence as a weight) was utilized in this study, and the primary finding was that this gross moist stability decreased significantly as the fraction of large-scale precipitation increased. In the simulations presented here, the zonal mean values of the gross moist stability defined in Eq. (4) behave similarly. These values, divided by $c_{p}$ to have units of temperature, averaged between $0^{\circ}$ and $5^{\circ}$ latitude are $7.0,4.0,2.5$, and $-2.7 \mathrm{~K}$ for the $\mathrm{RH}_{\mathrm{SBM}}=0.6$, $0.8,0.85$, and 0.95 cases, respectively. Discussion of the energy budgets of simulations with negative gross moist stability in the deep Tropics can be found in Frierson (2007).

Since the depth of convection (a primary determinant of the gross moist stability) changes somewhat across different phases of the wave (Fig. 5a), it is not clear a priori that the zonal mean gross moist stability will necessarily be representative of local values over the heart of the wave. We plot the composited values as a function of longitude averaged between $0^{\circ}$ and $5^{\circ}$ latitude for the $\mathrm{RH}_{\mathrm{SBM}}=0.6,0.8$, and 0.85 cases in Fig.

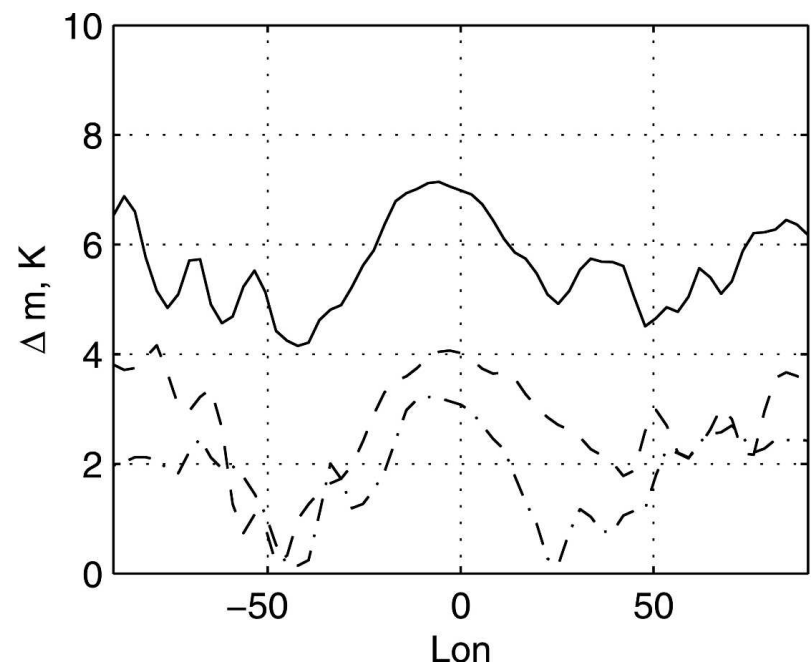

FIG. 12. Gross moist stability (divided by $c_{p}$ to have units of K) for the $\mathrm{RH}_{\mathrm{SBM}}=0.6$ simulation (solid), the $\mathrm{RH}_{\mathrm{SBM}}=0.8$ simulation (dashed), and the $\mathrm{RH}_{\mathrm{SBM}}=0.85$ simulation (dasheddotted).

12. The wave creates its own stability to some extent, with variations of several Kelvin from the positive to the negative phase, but the zonal mean values do remain relevant. The gross moist stability achieves a distinct maximum near the center of the updraft in each case, and decreases by a few degrees on either side of this. A decrease of gross moist stability is expected in regions with shallower depth of convection, where smaller values of the moist static energy in the midtroposphere can be tapped by outflow.

We next compare the values of the gross moist stability to the wave speeds. Since the gross moist stability is indicative of the atmospheric stability only where condensation occurs, we expect the gross moist stability averaged over the region of upward motion to be most important in determining the wave speed. The study of Sobel and Bretherton (2003) for instance uses the gross moist stability at the precipitation maximum only to estimate wave speeds. Averaging over the primary precipitation maximum (between -10 and 10 longitude relative to the base point), we estimate values of 6.9 , 3.9 , and $3.0 \mathrm{~K}$ for the $\mathrm{RH}_{\mathrm{SBM}}=0.6,0.8$, and 0.85 cases, respectively, all approximately equal to the zonally averaged value of the gross moist stability.

Using these values in Eq. (5) predicts equivalent depths of 63,36 , and $27 \mathrm{~m}$ for the $\mathrm{RH}_{\mathrm{SBM}}=0.6,0.8$, and 0.85 cases. These values are somewhat similar to the approximate values that we calculate for the waves of 40,30 , and $25 \mathrm{~m}$. Because of the range of wave speeds that are covered by the waves in the wavenumberfrequency spectra, and the uncertainty in the area to average the gross moist stability, we find this agreement 
adequate in explaining the basic change in Kelvin wave phase speeds in these simulations. If the zonally averaged gross moist stability is important in $\mathrm{RH}_{\mathrm{SBM}}=0.95$ case, it then seems reasonable that the Kelvin wave is eliminated in that case due to the lack of a positive gross moist stability.

The smaller gross moist stability as large-scale precipitation fraction increases can also explain the increased amplitude in precipitation of the waves in these cases. A smaller gross moist stability implies a greater sensitivity of divergence perturbations to surface or radiative forcing, in both time mean and transient situations: there is an increased sensitivity of velocity perturbations for fixed temperature perturbations with smaller gross moist stability in first baroclinic mode models such as Frierson et al. (2004).

It is important to note that in a vertically continuous model, the vertical structure of the heating can influence wave speeds in addition to the gross moist stability (Wang and Chen 1989). We have studied the changes in the vertical profiles in these various cases, and have found that the vertical structures stay very similar in these simulations. There is essentially no change in the simulations varying convective relaxation time, and a small shift toward more upper-tropospheric heating in the cases with more large-scale condensation. The latter change, however, is small and nonuniform as the large-scale fraction is increased. These results are highly suggestive that the vertical structure of heating is not a determinant of the changes in speed and amplitude of the Kelvin waves seen here.

\section{Conclusions}

In this study, we examine the effect of convection scheme parameters on equatorial Kelvin waves within a simplified moist general circulation model. A control simulation with this model produces strong, remarkably persistent convectively coupled Kelvin waves, with reasonable propagation speeds. The wave is powered by evaporation-wind feedback (Neelin et al. 1987; Emanuel 1987). Although evaporation-wind feedback is seen to be a source of energy for tropical ISV in some observations, it is only one of several possible sources of energy for ISV, with its complete relevance in powering the full equatorial wave spectrum yet to be determined. However we hope that the results here concerning the importance of the gross moist stability for the speed and amplitude of equatorial waves will be independent of the mechanisms that sustain the waves.

We find that the tropical variability is significantly affected by convection scheme parameters. For instance, the convective relaxation time serves to reduce the amplitude of the waves significantly, following the predictions of Emanuel (1993). Additionally, when the relaxation relative humidity is altered to change the fraction of convective versus large-scale precipitation (and hence the gross moist stability of the atmosphere), the Kelvin waves experience a reduction in phase speed and an increase in amplitude. There is nonuniform behavior in the amplitude however: the Kelvin wave is completely eliminated for simulations with nearly all large-scale condensation. We show that the gross moist stability (Neelin and Held 1987) is relevant for the wave speeds in these cases. The gross moist stability felt by the wave for the most part follows the zonal mean value of this quantity; hence a theory for changes in the zonal mean gross moist stability would explain to some extent changes in the wave propagation characteristics. The complex sensitivities of the wave speed to other parameters such as the convective relaxation time complicates this somewhat; however the results with the fraction of large-scale precipitation have been tested over a variety of parameter regimes with similar results.

The primary deviation from observations of the simulated waves is the lack of higher-mode vertical structure in the temperature, zonal wind, and other fields. This indicates that there is decreased importance of shallow convection and stratiform precipitation in the model. It remains to be seen if modifications to the convection scheme, guided by results from simple models that utilize a second baroclinic mode (Mapes 2000; Majda and Shefter 2001; Majda et al. 2004; Haertel and Kiladis 2004; Khouider and Majda 2006a,b,c, 2007), can reproduce the second baroclinic structures seen in observations and in cloud-resolving model simulations (Grabowski and Moncrieff 2001; Tulich et al. 2007). One possibility of an alteration to the convection scheme would be to increase the sensitivity to midtropospheric moisture, which may increase the importance of shallow convection by requiring shallow preconditioning of the midtroposphere before convection occurs.

It is also important to point out that these results may only hold true for this particular class of convection schemes, and our experience with full GCM convection schemes does show a range of sensitivities to a variety of parameters. However, there are analogs of the parameters of the SBM scheme in full GCM convection schemes that can be tested for these same effects, for instance, the convective relaxation time in the relaxed Arakawa-Schubert scheme (Moorthi and Suarez 1992). Additionally, the fraction of large-scale versus convective precipitation varies significantly among full GCMs from different modeling groups, and a recent study has 
shown a large sensitivity to this fraction with a full GCM in an idealized domain (Held et al. 2007). More experiments are required to find out how relevant these results are to full GCMs.

The simplified radiative transfer scheme in this model may also have an effect on the waves: Wang and Chen (1989) show that moist Kelvin wave speeds can be sensitive to the strength of the radiative cooling, and the vertical structure of the radiative cooling is different in the gray scheme than in full radiative transfer schemes as well. Cloud- and water vapor-radiative feedbacks may also impact wave propagation.

There are some important possible implications of this study that we plan on testing in more sophisticated models. First we find that, in this model, increasing the fraction of large-scale precipitation can provide a quick fix for the typical GCM problem of too fast, too weak tropical ISV. This result should be combined with the accompanying results of Frierson (2007) however, who show that increases in the fraction of large-scale condensation increase sensitivities of the tropical mean climate to parameters and resolution [see also the full GCM radiative-convective equilibrium study of Held et al. (2007), who find similar sensitivities in this geometry]. In this sense, when the model's tropical variability is improved, the mean climate is degraded, which is a common problem for full GCMs as well. Future research directions on this topic involving more complex models would include integrated analysis of both the mean climate and variability of GCMs, using the gross moist stability as an important diagnostic for both, to help improve our understanding of these models and their deficiencies.

Acknowledgments. Much of this work was inspired by the author's attendance at the NCAR IMAGe Workshop on Multiscale Interactions in the Tropics to Midlatitudes in September 2005. I additionally thank R. Pierrehumbert for many helpful discussions. This work is supported by the NOAA Climate and Global Change Postdoctoral Fellowship, administered by the University Corporation for Atmospheric Research. This research was also supported in part by the Climate Systems Center of the University of Chicago, under National Science Foundation Grant ATM-0121028.

\section{REFERENCES}

Arakawa, A., 2004: The cumulus parameterization problem: Past, present and future. J. Climate, 17, 2493-2525.

Betts, A. K., 1986: A new convective adjustment scheme. Part I: Observational and theoretical basis. Quart. J. Roy. Meteor. Soc., 112, 677-692.

_, and M. J. Miller, 1986: A new convective adjustment scheme. Part II: Single column tests using GATE wave, BOMEX, and arctic air-mass data sets. Quart. J. Roy. Meteor. Soc., 112, 693-709.

Bretherton, C., M. E. Peters, and L. E. Back, 2004: Relationships between water vapor path and precipition over the tropical oceans. J. Climate, 17, 1517-1528.

Emanuel, K. A., 1987: An air-sea interaction model of intraseasonal oscillations in the tropics. J. Atmos. Sci., 44, 2324-2340. , 1993: The effect of convective response time on WISHE modes. J. Atmos. Sci., 50, 1763-1775.

_ J. D. Neelin, and C. S. Bretherton, 1994: On large-scale circulations in convecting atmospheres. Quart. J. Roy. Meteor. Soc., 120, 1111-1143.

Frierson, D. M. W., 2007: The dynamics of idealized convection schemes and their effect on the zonally averaged tropical circulation. J. Atmos. Sci., 64, 1959-1976.

— A. A. Majda, and O. M. Pauluis, 2004: Large-scale dynamics of precipitation fronts in the tropical atmosphere: A novel relaxation limit. Commun. Math. Sci., 2, 591-626.

—, I. M. Held, and P. Zurita-Gotor, 2006: A gray-radiation aquaplanet moist GCM. Part I: Static stability and eddy scale. J. Atmos. Sci., 63, 2548-2566.

,-- , and - , 2007: A gray-radiation aquaplanet moist GCM. Part II: Energy transports in altered climates. J. Atmos. Sci., 64, 1680-1693.

Garner, S. T., D. M. W. Frierson, I. M. Held, O. M. Pauluis, and G. K. Vallis, 2007: Resolving convection in a global hypohydrostatic model. J. Atmos. Sci., 64, 2061-2075.

Gill, A. E., 1980: Some simple solutions for heat induced tropical circulations. Quart. J. Roy. Meteor. Soc., 106, 447-462.

Grabowski, W. W., and M. W. Moncrieff, 2001: Large-scale organization of tropical deep convection in two-dimensional explicit numerical simulations. Quart. J. Roy. Meteor. Soc., 127, 445-468.

Haertel, P. T., and G. N. Kiladis, 2004: Dynamics of two-day equatorial waves. J. Atmos. Sci., 61, 2707-2721.

Hayashi, Y., 1982: Space-time spectral analysis and its application to atmospheric waves. J. Meteor. Soc. Japan, 60, 156-171.

Held, I. M., M. Zhao, and B. Wyman, 2007: Dynamic radiativeconvective equilibria using GCM column physics. J. Atmos. Sci., 64, 228-238.

Khouider, B., and A. J. Majda, 2006a: A simple multicloud parameterization for convectively coupled tropical waves. Part I: Linear analysis. J. Atmos. Sci., 63, 1308-1323.

—, and —_, 2006b: Model multi-cloud parameterizations for convectively coupled waves: Detailed nonlinear wave evolution. Dyn. Atmos. Oceans, 42, 59-80.

— , and — 2006c: Multicloud convective parameterizations with crude vertical structure. Theor. Comput. Fluid Dyn., 20, 351-375.

— convectively coupled tropical waves. Part II: Nonlinear simulations. J. Atmos. Sci., 64, 381-400.

Lee, M.-I., I.-S. Kang, J.-K. Kim, and B. E. Mapes, 2001: Influence of cloud-radiation interaction on simulating tropical intraseasonal oscillation with an atmospheric general circulation model. J. Geophys. Res., 106, 14 219-14 233.

,$- \ldots$, and B. E. Mapes, 2003: Influence of cumulus convection parameterization on aqua-planet AGCM simulations of tropical intraseasonal variability. J. Meteor. Soc. Japan, 81, 963-992.

Lin, J., and Coauthors, 2006: Tropical intraseasonal variability in 
14 IPCC AR4 climate models. Part I: Convective signals. J. Climate, 19, 2665-2690.

Lindzen, R. S., 1974: Wave-CISK in the Tropics. J. Atmos. Sci., 31, $156-179$.

Majda, A. J., and M. Shefter, 2001: Models of stratiform instability and convectively coupled waves. J. Atmos. Sci., 58, 15671584 .

- B. Khouider, G. N. Kiladis, K. H. Straub, and M. G. Shefter, 2004: A model for convectively coupled tropical waves: Nonlinearity, rotation-, and comparison with observations. J. Atmos. Sci., 61, 2188-2205.

Mapes, B. E., 2000: Convective inhibition, subgrid-scale triggering energy, and stratiform instability in a toy tropical wave model. J. Atmos. Sci., 57, 1515-1535.

Matsuno, T., 1966: Quasi-geostrophic motions in the equatorial area. J. Meteor. Soc. Japan, 44, 25-43.

Moorthi, S., and M. J. Suarez, 1992: Relaxed Arakawa-Schubert: A parameterization of moist convection for general circulation models. Mon. Wea. Rev., 120, 978-1002.

Neelin, J. D., and I. M. Held, 1987: Modeling tropical convergence based on the moist static energy budget. Mon. Wea. Rev., 115, 3-12.

— vective adjustment and the Madden-Julian oscillation. Part I: Analytical theory. J. Atmos. Sci., 51, 1876-1894.

— model-Formulation. J. Atmos. Sci., 57, 1741-1766.

—, I. M. Held, and K. H. Cook, 1987: Evaporation-wind feedback and low-frequency variability in the tropical atmosphere. J. Atmos. Sci., 44, 2341-2348.

Numaguti, A., 1993: Dynamics and energy balance of the Hadley circulation and tropical precipitation zones: Significance of the distribution of evaporation. J. Atmos. Sci., 50, 1874-1887.

Raymond, D. J., 2001: A new model of the Madden-Julian oscillation. J. Atmos. Sci., 58, 2807-2819.

Slingo, J. M., and Coauthors, 1996: Intraseasonal oscillations in 15 atmospheric general circulation models: Results from an AMIP diagnostic subproject. Climate Dyn., 12, 325-357.

Sobel, A. H., and C. S. Bretherton, 2003: Large-scale waves interacting with deep convection in idealized mesoscale model simulations. Tellus, 55, 45-60.
Straub, K. H., and G. N. Kiladis, 2002: Observations of a convectively coupled Kelvin wave in the eastern Pacific ITCZ. $J$. Atmos. Sci., 59, 30-53.

— and - 2003: The observed structure of convectively coupled Kelvin waves: Comparison with simple models of coupled wave instability. J. Atmos. Sci., 60, 1655-1668.

Tian, B., and V. Ramanathan, 2003: A simple moist tropical atmosphere model: The role of cloud-radiative forcing. J. Climate, 16, 2086-2092.

Tokioka, T., K. Yamazaki, A. Kitoh, and T. Ose, 1988: The equatorial 30-60 day oscillation and the Arakawa-Schubert penetrative cumulus parameterization. J. Meteor. Soc. Japan, 66, 883-901.

Tulich, S. N., D. A. Randall, and B. E. Mapes, 2007: Verticalmode and cloud decomposition of large-scale convectively coupled gravity waves in a two-dimensional cloud-resolving model. J. Atmos. Sci., 64, 1210-1229.

Waliser, D. E., K. M. Lau, W. Stern, and C. Jones, 2003: Potential predictability of the Madden-Julian oscillation. Bull. Amer. Meteor. Soc., 84, 33-50.

Wang, B., 1988: Dynamics of tropical low-frequency waves: An analysis of the moist Kelvin wave. J. Atmos. Sci., 45, 20512065.

- 2005: Theory. Intraseasonal Variability in the AtmosphereOcean Climate System, W. K. M. Lau and D. E. Waliser, Eds., Springer-Praxis, 307-360.

_ , and J. Chen, 1989: On the zonal-scale selection and vertical structure of equatorial intraseasonal waves. Quart. J. Roy. Meteor. Soc., 115, 1301-1323.

— Rossby wave on an equatorial $\beta$-plane. J. Atmos. Sci., 47, 397-413.

Wheeler, M., and G. N. Kiladis, 1999: Convectively coupled equatorial waves: Analysis of clouds and temperature in the wavenumber-frequency domain. J. Atmos. Sci., 56, 374-399.

- _ — , and P. J. Webster, 2000: Large-scale dynamical fields associated with convectively coupled equatorial waves. $J$. Atmos. Sci., 57, 613-640.

Yu, J.-Y., and J. D. Neelin, 1994: Modes of tropical variability under convective adjustment and the Madden-Julian oscillation. Part II: Numerical results. J. Atmos. Sci., 51, 1895-1914. 